\title{
Vadilerde Fiziki Yapıya Bağlı Bitkilendirme Olanakları, Ankara Büyükesat Vadisi Örneği*
}

\author{
Plantation Opportunities at Valleys in the Basis of Physiographical Conditions: Ankara \\ Büyükesat Valley Case
}

\author{
Tahsin YILMAZ ${ }^{1}$ \\ ${ }^{1}$ Ankara Üniversitesi Ziraat Fakültesi Peyzaj Mimarlı̆̆ı Bölümü, Dışkapı, 06110, Ankara
}

\begin{abstract}
Özet: Vadiler kentlerin önemli topoğrafik yapılarıdır ve diğer yeryüzü şekillerine göre farklı özelliklere sahiptir. Bir çok vadi yakın çevresindeki iklim tipinden farklı bir mikroklimaya sahip olabilmektedir. İklimsel farklılıklar ise, vadilerde bulunan vejetasyon yapısının farklı olmasına sebep olmaktadır. Dolayısı ile vadilerde yapılması düşünülen bitkilendirme çalışmalarında bu farklılık ve nedenleri önem kazanmaktadır. Bu makalede vadilerdeki bitki oluşumuna etki eden etmenler, Büyükesat vadisi örneğinde incelenmiş ve sonuç olarak vadi içinde yapılması muhtemel bitkilendirme çalışmaları için uygun - uygun olmayan alanlar ve ekolojik şartlar belirlenmiştir.
\end{abstract}

Anahtar Kelimeler: Vadi, ekolojik koşullar, bitkilendirme, Büyükesat Vadisi.

Abstract: Valleys are important topographic elements in the cities and they have different characteristics than other earth shapes. Many of valleys may have distinguished climatic conditions than near surroundings. Because of this climatic dissimilarity, vegetation structure is also different in valley. Therefore these differences and their reasons affect planting efforts in valleys. In this article, the factors that affect the plant growth conditions in valleys were investigated in the example of Büyükesat Valley case. As a result, the areas and ecological conditions which are suitable or not suitable for potential plantation were identifies.

Key Words: Valley, ecological conditions, plantation, Büyükesat Valley.

\section{Giriş}

Vadiler yeryüzündeki coğrafi şekillerin en tipik olanlarındandır. Yağmurun buharlaşmadan fazla olduğu nemli iklim bölgelerinin her yerinde vadiler geniş yer tutar. Bunun yanında diğer iklim tiplerinde de sıklıkla görülürler. Vadiler coğrafi olarak ana çizgileri ile devamlı inişleri bulunan uzun çukurluklardır. Vadilerin önemleri bu çukurların kapalı değil açık olmasıdır. Vadiler akarsuların oymasından ve aşındırmasından doğmuş şekillerdir (İzbırak 1977).

Vadiler fiziksel yapılarından dolayı, yakın çevresindeki iklimden farklı karakterde bir iklim yapısı gösterebilmektedirler. Vadi içinde oluşan bu mikroklimalar alışılageldik vejetasyon örtüsünün dışında farklı bitki türlerinin yetişmesine ve bitkilerin farklı gelişmesine olanak sağlamaktadır.

$\mathrm{Bu}$ farklılıklar, içe dönük yapısıyla vadilerin farklı bakarları olmasından, akarsu yatağı ve yamaçları arasında bulunan yükseklik farklarından, vadi içinde oluşan hava akımlarından, güneşin konumuna göre oluşan gölgelik alanlar ve güneşlenme sürelerinden vb. oluşmaktadır.

$\mathrm{Bu}$ makalede, belirtilen öğelerin bitkilendirme olanakları üzerindeki etkileri Ankara Büyükesat Vadisi örneğinde incelenmiş ve bunlara bağlı bitkilendirme olanakları araştırılarak, öneriler getirilmiştir.

\section{Materyal ve Yöntem}

Çalışma alanı olarak Büyükesat Vadisi ele alınmıştır. Çalışma materyali olarak alana ait 1990 tarihli 1/25000 ölçekli topoğrafik haritalar Çevre ve Orman Bakanlığı'ndan, 1/5000 ölçekli imar planları Ankara Büyükşehir Belediyesi ve Çankaya Belediyesi İmar Müdürlüklerinden, iklim verileri Meteoroloji İşleri Genel Müdürlügü’nden elde edilerek kullanılmışlardır.

Yöntem olarak, vadiler ve fiziksel yapıya bağlı olarak vadilerdeki bitki yapılarında olabilecek değiş̧iklikler incelenmiş, sayısal haritalar üzerinden bilgisayar desteği alınarak çalışma alanına ait eğim, bakı, yükseklik, gölgelik alanlar ve don riski taşıyan alanlar haritaları üretilmiş, aynı zamanda

\footnotetext{
* Büyükesat Vadisi'nin Kent Peyzajı ve Tasarımı Kapsamında İncelenmesi adlı doktora tezinden üretilmiştir.
} 
alana ait iklim verileri alınarak Büyükesat Vadisi üzerindeki bitkilendirme olanakları hakkında sonuçlara ulaşılmaya çalışılmıştır.

Çalışma esnasında sayısallaştırma ve analizlerde Autocad 2004, Arcview 3.2 ve ArcGIS 9.1 programından, görselleştirme ve animasyonda Photoshop ve 3d Studio Max programlarından yararlanılmıştır.

\section{Bulgular}

Çalışma alanına ait bilgiler elde etmek amacı ile iklim verileri, yükseklik, eğim ve bakı grupları haritaları, güneşin mevsimlik konumu ve gölgelik alanlar ve vadi içi rüzgar hareketleri incelenmiştir.

\section{1. Çalışma Alanı}

Büyükesat Vadisi $39^{\circ} 57.0^{\prime}$ enlem ve $32^{\circ} 51.0^{\prime}$ boylamdaki Ankara ilinde bulunmaktadır. Ankara'nın güneydoğu istikametinde Çankaya İlçesi sınırlarında yer alan vadi, Harita Genel Komutanlı̆̆g'ndan elde edilen $1 / 25000$ ölçek ve I29b1, I29b2, I29b3 ve I29b4 no'lu topografik haritaları kapsamaktadır. Çalışma alanı, İmrahor Vadisi İncesu Deresi'ni besleyen Büyükesat Deresi'nin yarattı̆ğ bir vadi konumundadır (Şekil1.)
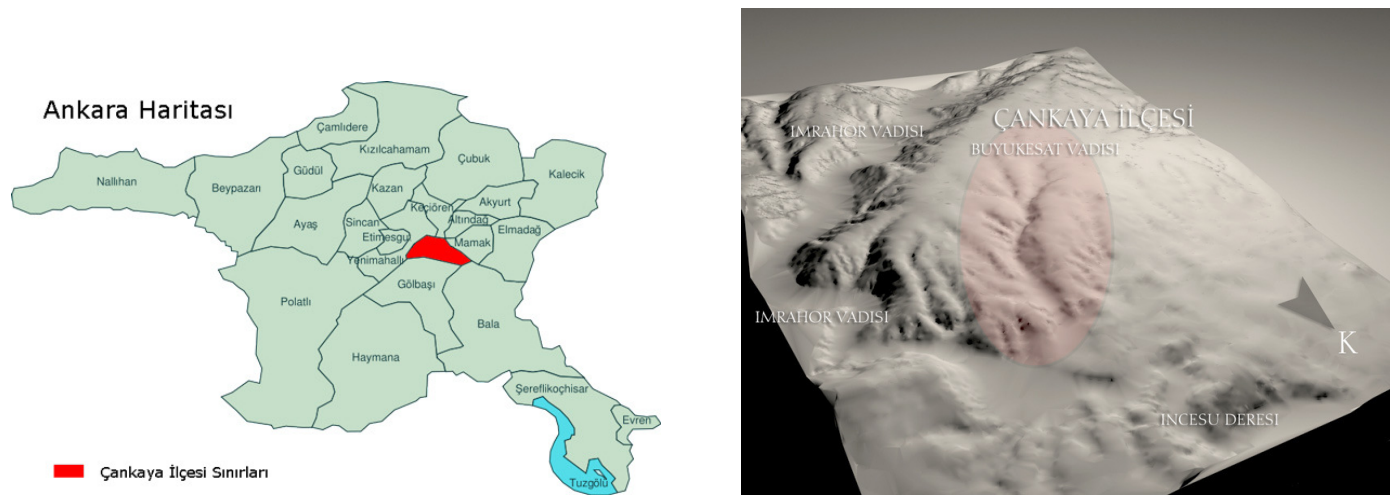

Şekil 1 Çankaya İlçesi sınırları ve Büyükesat Vadisi’nin konumu.

\section{2. İklim Verileri}

İklim; atmosfer, hidrosfer, yer yüzeyi, biyosfer ve buzullar olmak üzere beş temel bileşenden oluşan interaktif bir sistemdir. Bu bileşenler pek çok diş etken ve mekanizmadan etkilenmektedir. İnsan aktiviteleri de iklim sistemini doğrudan etkileyen bir etken olarak nitelendirilmektedir (Yüksel, 2005).

Çalışma alanı yakın çevresinde İç Anadolu Bölgesi’nin step iklimi hüküm sürmektedir. Hava yazları sıcak ve kurak, kışları ise sert ve yağışlıdır.

Meteoroloji İşleri Genel Müdürlüğünden alınan ve çalışma alanına denk konumda olan verilere göre (Şekil 2) ortalama en düşük sıcaklık Aralık, Ocak ve Şubat aylarında görülmektedir. Sadece bu 3 ayda ortalama sıcaklıklar eksi değerlerdedir.

Mayıs ve Ekim ayları arasında kar yağışı görülmemiştir. Ancak kar yağışının olduğu diğer aylarda bile $5 \mathrm{~cm}$ derinlikteki toprağın ortalama sicaklı̆g $13,5^{\circ} \mathrm{C}$ olup yıl boyunca eksi değerlere düşmemektedir. Ortalama toplam yağış miktarı $400.2 \mathrm{~mm}$ olup, ortalama kar yağışıl gün sayısı 31.5 gündür. Ortalama rüzgar hızı $1.98 \mathrm{~m} / \mathrm{sn}$ 'dir. Vadi içinde topografik özelliklere bağlı olarak sabah ve akşam saatlerinde hava akımları meydana gelmektedir.Yıllık ortalama bağıl nem $\% 60$ dır. 


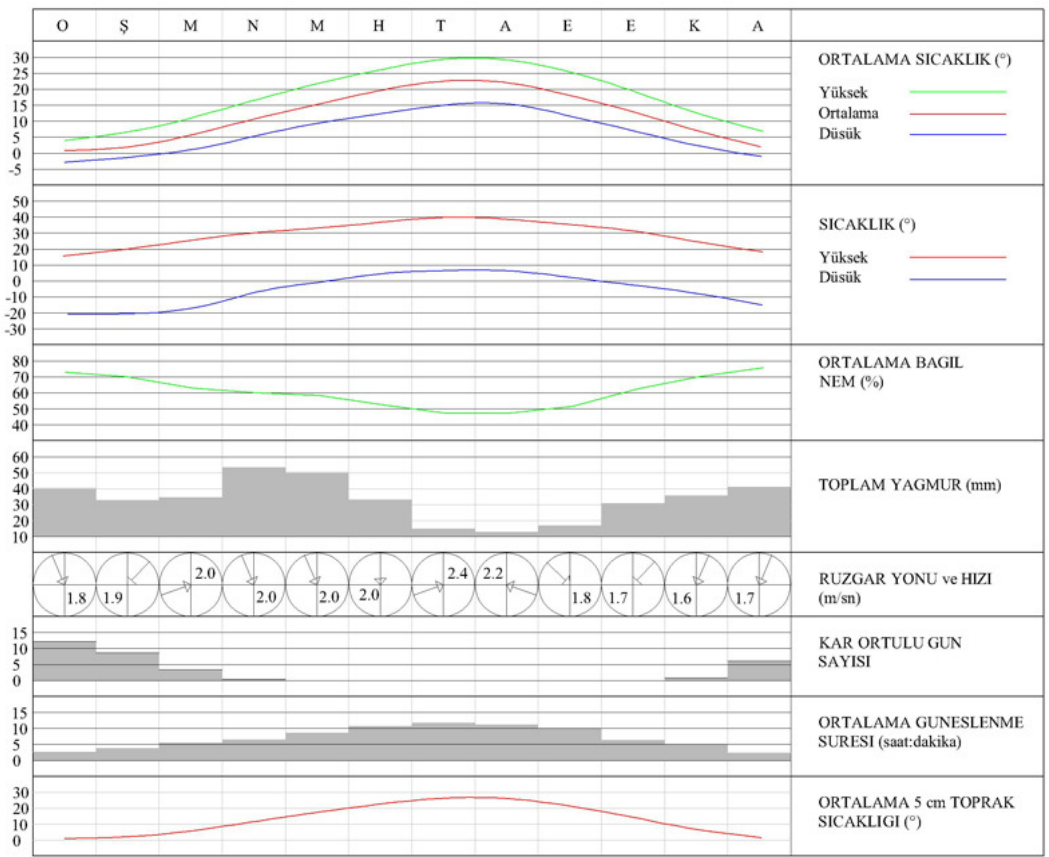

Şekil 2. Çalışma alanı iklim verileri (Kaynak: Meteoroloji İşleri Gn. Müd.).

\subsection{Yükseklik Grupları Analizi}

1/25000 ölçekli halihazır haritalardan sayısallaştırılan eşyükselti eğrileri üzerinden hareketle ve ArcGIS 9.1. programı yardımıyla, çalışma alanına ait yükseklik grupları analizi yapılarak alanın rakım bilgileri elde edilmiştir (Şekil 3). Bu analize göre alanın en yüksek noktası 1126 kotunda ve alanın kuzey batısında, en düşük noktası ise 897 m. kotu ile Büyükesat Deresi'nin Şemsettin Günaltay Caddesi ile kesişme noktasında yer almaktadır. Çalışma alanı Ankara'nın ortalama rakımı olan $850 \mathrm{~m}$. kotundan daha yüksek bir seviyede bulunmaktadır. Çalışma alanının en yüksek ve en düşük noktaları arasında 229 m. yükseklik farkı bulunmaktadır.

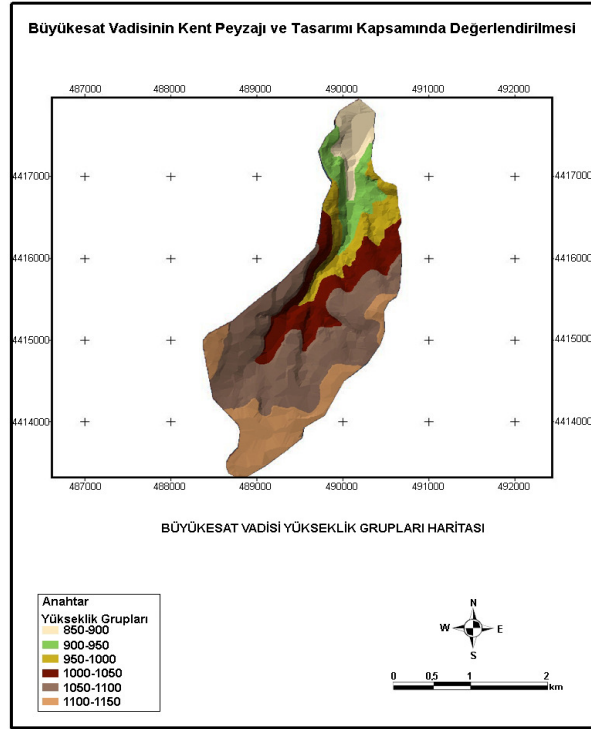

Şekil 3. Büyükesat vadisi yükseklik grupları haritası. 


\subsection{Eğim Grupları Analizi}

Doğal yapı itibarı ile eğimli alanları bulunan vadi oluşumlarında, topoğrafyanın doğru anlaşılabilmesi için eğim haritası önem taşıyan bir unsur olmaktadır. Eğimin miktarı, yapılaşma, drenaj, spor faaliyetleri, rekreatif faaliyetler, bitkilendirme gibi çalışmalarda dikkate alınacak önemli bir faktör olmaktadır. Bu sebeple alan üzerinde eğim analizi yapılmıştır (Şekil 4).

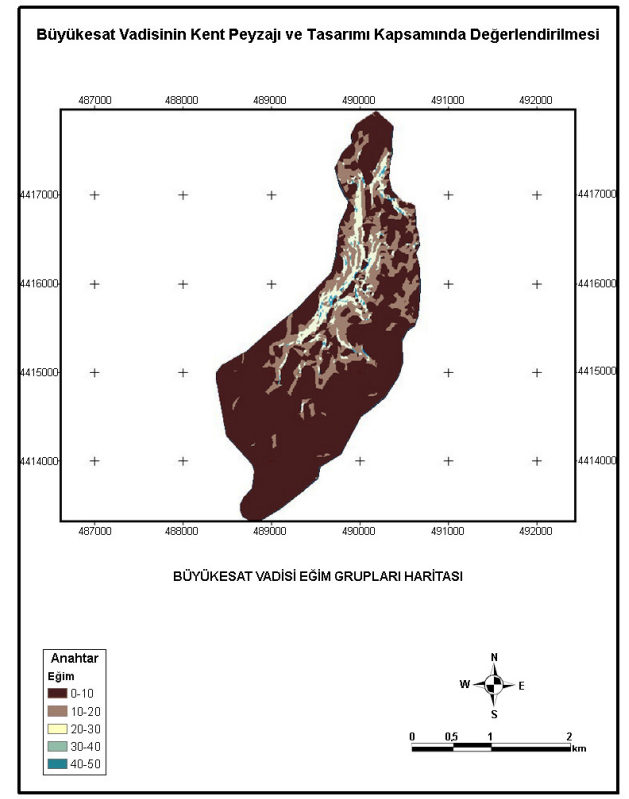

Şekil 4. Büyükesat vadisi eğim grupları haritası.

Alanın genel eğim durumunun gözlenebilmesi için 10'ar dilimlik aralıklarla eğimli alanlar belirlenmiştir. $\mathrm{Bu}$ analizde yüzde olarak 0-10, 10-20, 20-30, 30-40 ve 40-50 eğime sahip alanların yerleri belirlenmiştir.

Analiz sonuçlarına göre çalışma alanının \%72,2'lik bölümü \%0-10'luk bir eğime sahiptir. Söz konusu alanlar genellikle vadi tabanı ve yakın çevresinden uzakta konumlanmış ve halihazır durumda yapılaşmış alanlardır.

Çalışma alanının \%20'lik bölümü eğimi \% 10-20 arasında bulunan alanlardır. Bu alanlar vadinin yüksek eğime sahip iki yakasının hemen çevresinde yoğunlaşmış alanlardır.

Çalışma alanının \%7'lik bolümü eğimi \% 20-30 arasında olan alanlardır, söz konusu alanlar vadinin iki yakasının büyük bölümünü oluşturmaktadır.

Alanın \%0.7'lik bölümü \% 30-40 ve \% 001'lik bölümü ise \% 40-50 arası yüksek eğime sahip alanlardır. Bu alanlar da yine vadinin iki yakasında seyrek olarak konumlanmış bulunmaktadırlar.

\subsection{Bakı Grupları Analizi}

Vadiler üzerinde yapılan çalışmalarında, vadinin iki yakasının farklı yönlere bakıyor olmasından dolayı bakı analizi önem kazanmaktadır.

Bakı analizi ile istenen yöne bakan arazi bölgelerini gösteren poligon detaylar oluşturulup bu detaylar gerektiğinde diğer analiz türleri ile entegre bir biçimde kullanılabilmektedir. Arazi eğimine bağlı olarak belirlenen bakı değerleri genel bir sınıflandırmayla, kuzey, güney vb. bakı aralıkları tespit edilebilmektedir. Bakı, arazide bulanan detaylara ait yüzeylerin bakış yönlerinin belirlenmesinde kullanılan sayısal bir arazi analiz şeklidir (Anonim, 2007). 
Güneşten yararlanma, güneşten korunma, bitkilendirme, yapısal elemanların (konutlar, spor alanları vs) konumlandırılmasında bakı analizinden yararlanılmaktadır. Bu sebeple Arc GIS 9.1. programı yardımı ile alana ait bakı analizi yapılmıştır (Şekil 5).

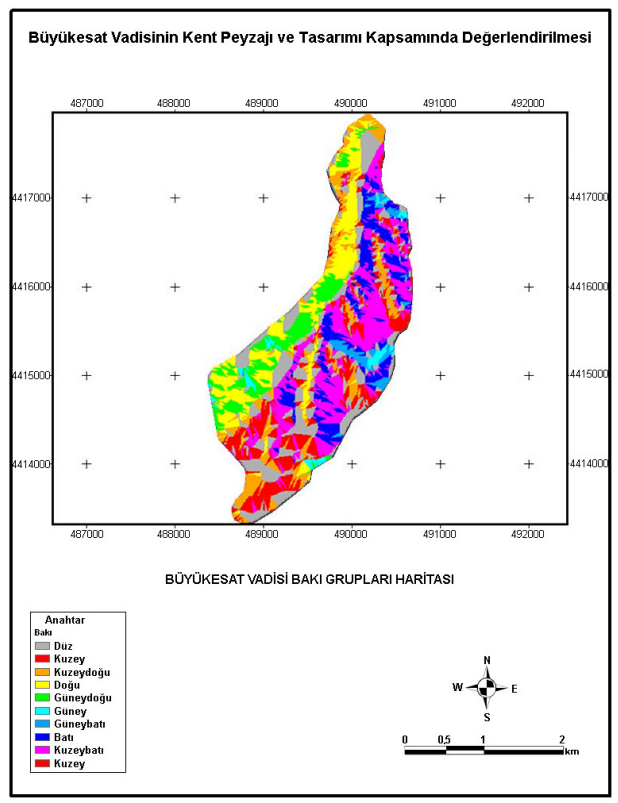

Şekil 5. Büyükesat vadisi bakı grupları haritası.

Bakı analizinde akarsu yatağı ve kolları net olarak görülmekte, akarsuyun batısında kalan sarı ve yeşil renkler doğu ve güney doğu bakarlı olurken, akarsuyun doğu ve kuzeyinde kalan diğer alanlar, genelde kuzey, batı ve kuzeybatı bakarlı alanlar olarak saptanmıştır.

\subsection{Güneşin Mevsimlik Konumu ve Gölgelik Alanlar}

Vadi, topografik olarak düz bir yapıda olmadığı için güneş konumuna bağlı olarak ortaya çıkan gölgelik alanlar önem kazanmaktadır. Bu alanların tespiti için Ankara Üniversitesi Fen Fakültesi Uzay Bilimleri ve Astronomi Bölümü’nden konuyla ilgili bilgi alınmış (Usno 2007), yıl boyunca güneşin Ankara için konumları belirlenerek, 4 mevsim için çalışma alanını içeren gölgelik alanlar belirlenmeye çalışılmıştır.

Değerler hesaplanırken kış mevsimi için 21 Ocak, ilkbahar için 21 Nisan, yaz için 21 Temmuz ve sonbahar mevsimi için 21 Ekim tarihleri kaynak veri olarak alınmıştır. Hesaplamalarda güneşin Ankara'ya geliş açısı hesaplanırken, güneşin kente göre en dik olduğu konumdaki değeri $\left(180^{\circ}\right)$ dikkate alınmıştır. Bu çalışmalara göre Ankara'ya güneş en düşük açıda kış aylarında $26.7^{\circ}$ ile gelmektedir (Şekil 6).

Ankara'ya güneşin en dik açıyla geldiği mevsim yaz ayı olmakta ve 21 Haziran tarihinde güneş $73.5^{\circ}$ ile en dik konuma gelmektedir. Bu tarihte 04:20 de doğan güneş 19:20 de batarak 15 saat Ankara' yı 1şıtmaktadır. İlkbaharda yaklaşık $61.9^{\circ}$ ile gelen güneş, sonbahar mevsiminde ise yaklaşık $39.5^{\circ}$ derece ile konumlanmaktadır (Şekil 7 ve 8). 


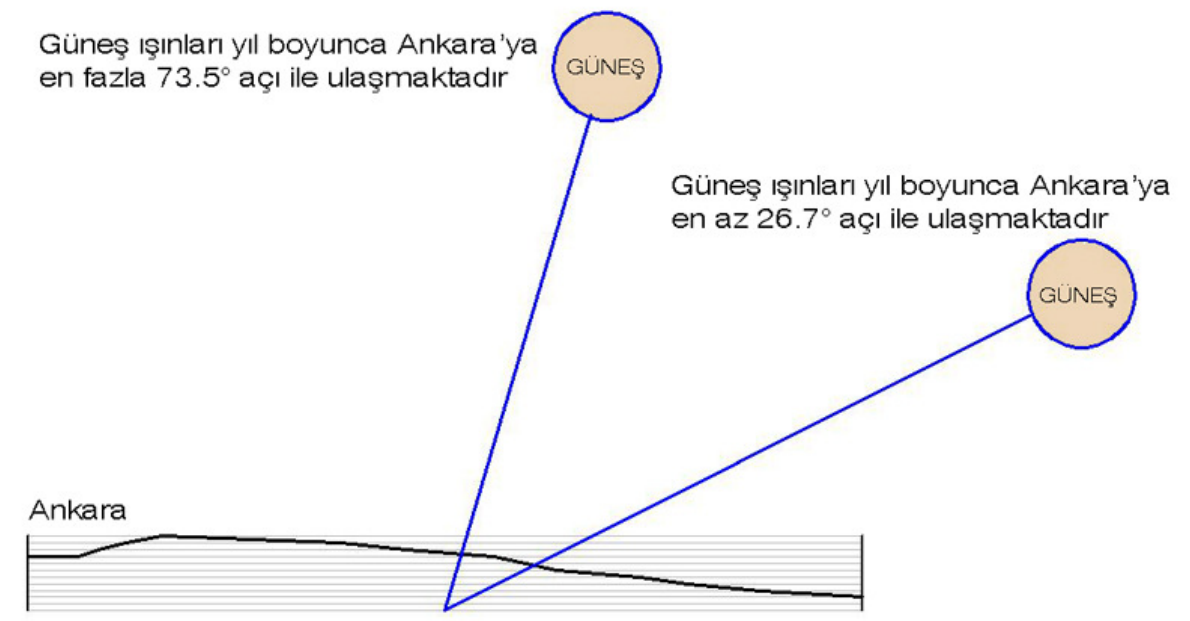

Şekil 6. Güneşin yıl boyu Ankara'yla yaptığı en az ve en çok açılar.

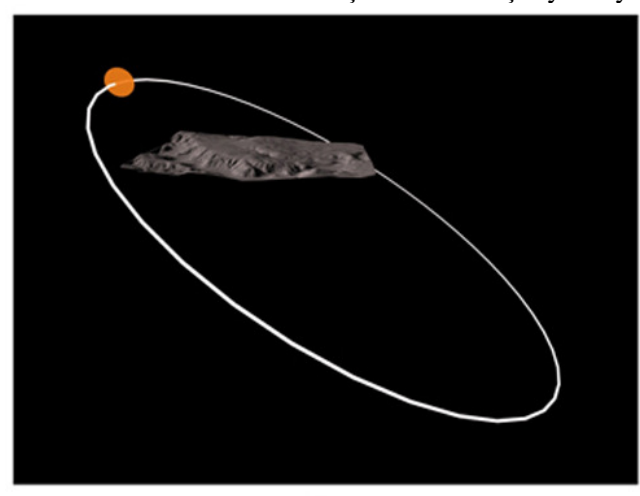

KIS

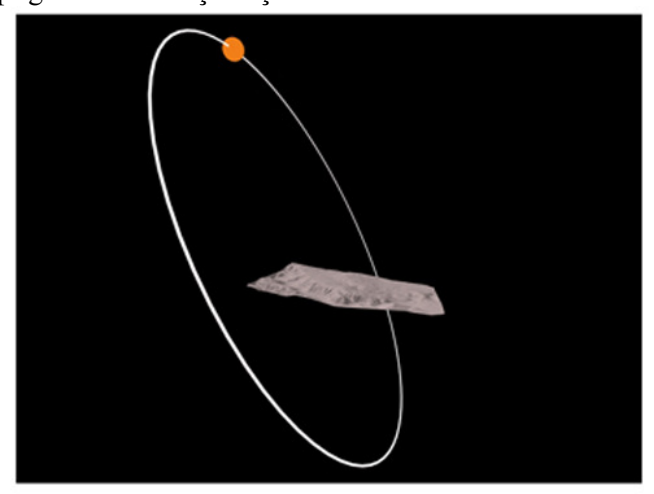

ILKBAHAR

Şekil 7. Güneşin çalışma alanına göre mevsimlik konumları.

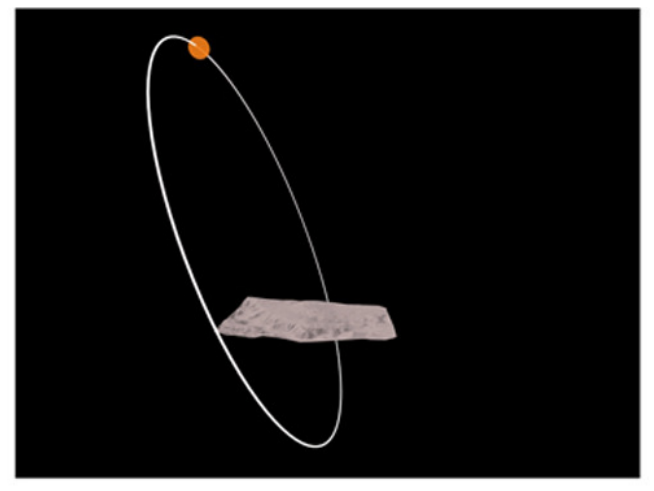

YAZ

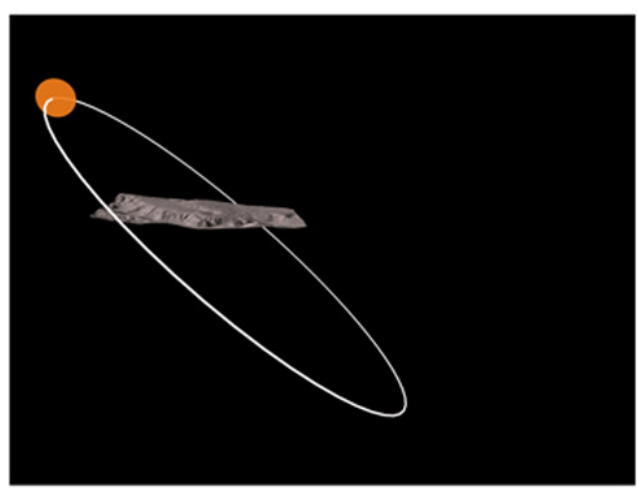

SONBAHAR

Şekil 8. Güneşin çalışma alanına göre mevsimlik konumları.

Güneşin konumlarına göre vadi içinde, mevsimlere bağlı gölgelik alanlar oluşmaktadır (Şekil 9 ve10). Bu alanlardan bazıları gün içinde belli saatlerde güneş 1şı̆̆ı alamazken, bazıları gün boyunca hatta tüm yıl boyunca hiç güneş ışığı alamamaktadırlar. 


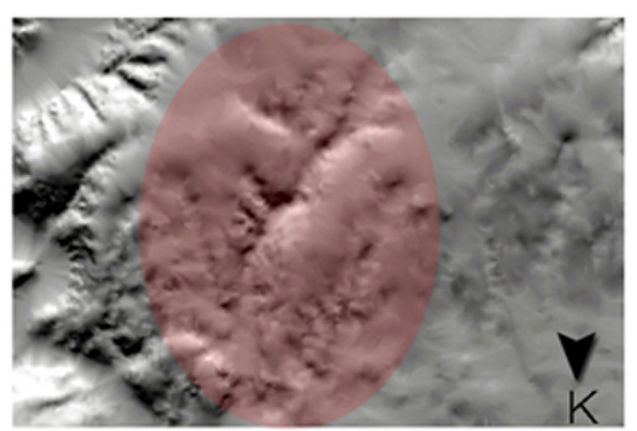

Şekil 9. Güneşe bağlı gölgelik alanlar

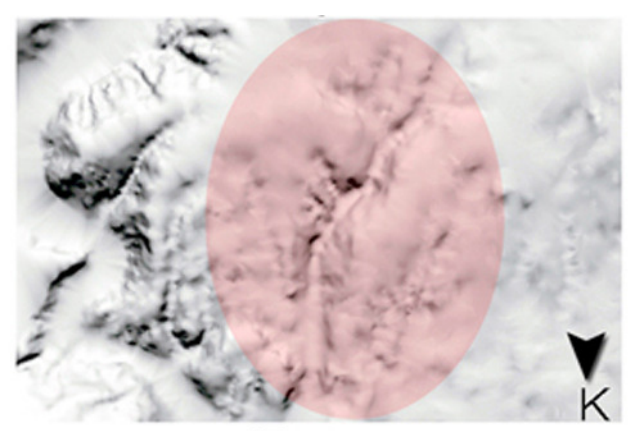

ilkbahar mevsimi

Söz konusu alanlar topografik yapıdan ve güneşin yörüngesinden dolayı ışı alamamakta ve gölgede kalmaktadır. Dört mevsime bağlı olarak sürekli gölgede kalan alanlar ise Şekil 11'de gösterilmiştir. Bu alanlar güneşin yıllık hareketi boyunca hiç güneş almamaktadır.

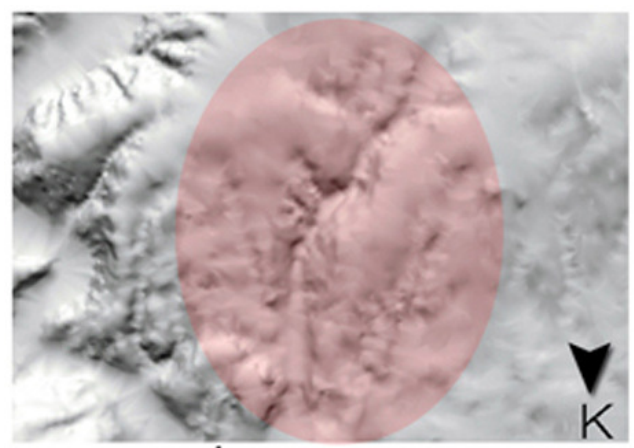

Şekil 10. Güneşe bağlı gölgelik alanlar

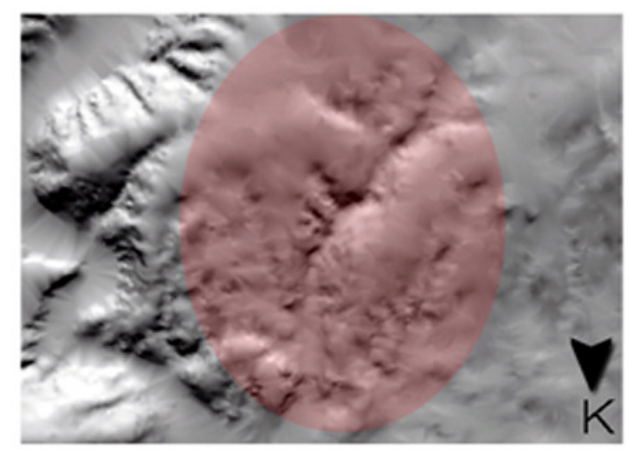

sonbahar mevsimi

Bu veri, gerek yerleşim alanları planlamasında, gerek bitkilendirme çalışmalarında, gerekse alan üzerinde yapılması muhtemel diğer bütün çalışmalarda temel verilerden biri olarak kullanılmalıdır.

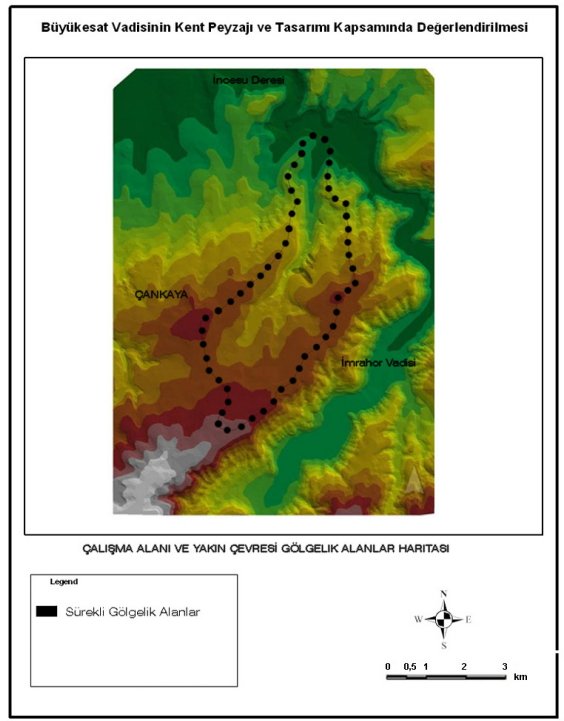

Şekil 11 Güneşin konumuna bağlı olarak oluşan sürekli gölgelik alanlar. 


\subsection{Vadi İçi Rüzgar Hareketleri}

Akarsu vadi peyzajları morfolojik yapıya bağlı olarak çevrelerine oranla farklı iklimsel karakterlere sahiptirler. Vadiler lokal hava akımlarının oluşmasına neden olurlar. Sabah erken saatlerde vadi tabanından yamaçlara doğru olan hava hareketi, gece geç saatlerde tersine dönerek vadi tabanına doğru hareketlenir, benzer şekilde akşamüzeri hava hareketi vadinin tabanı boyunca akarsu kaynağına doğru hareketlenirken gece geç saatlerde bu hareket tersine dönerek akarsu ağzına doğru hareketlenmektedir (Şahin, 1996).

Havanın yoğunluk ve basıncı ile nispi nem değerini doğrudan etkileyen en önemli faktör sıcaklıktır. Bir başka ifade ile hava sıcaklığındaki değişiklikler; havanın yoğunluk, basınç ve nispi nem oranlarının değişmesine neden olur. Sıcaklığı artan havanın yoğunluğu azalır ve yukarı doğru yükselir. Yükselen havanın yerini ise, serin ve yoğunluğu fazla olan hava doldurur (Eser ve Geçit, 2007).

$\mathrm{Bu}$ hava hareketleri bazı aktivitelerin uygulanmasında sınırlayıcı olabilir (Şekil 12). Geceleri vadi tabanına doğru akan hava hareketleri soğuktur ve tabanda don riskini artırır.

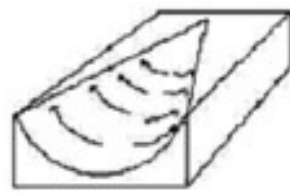

Sabah erken

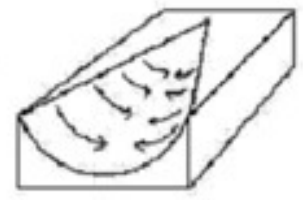

Gece

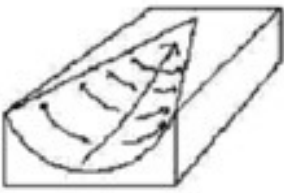

Aksam uzeri

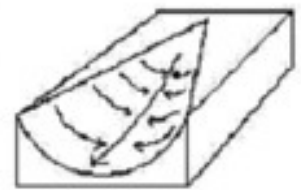

Gece gec saatler

Şekil 12 Günün değişen zamanlarında vadi içi hava akımları (Şahin 1996).

Krusche et al.(1982)'e göre kent içi ve yakın çevresindeki açıklık gece boyunca soğuyan hava gittikçe ağırlaşarak yavaş yavaş yamaçlardan aşağıya doğru hareket eder (1m/saat) (Yüksel 2005). Aşağı kesimlerde havanın birikmesiyle rüzgar hızını kaybeder ve bu kesimlerde soğuk hava koşulları hakim olur. Vadi tabanları ve havzalarda biriken bu soğuk hava durağan hale gelerek gece boyunca niteliği pek değişmeden etkin bir şekilde kalır. Soğuk havanın etkin olduğu bu kesimler büyük ölçüde don tehlikesiyle karşı karşıya kalır (Şekil 13). Aynı zamanda durağan hava içerisinde tozlar ve gazların da birikmesiyle söz konusu soğuk hava kütlesinin aynı zamanda kirliliği de önemli ölçüde $\operatorname{artar}$ (Yüksel 2005).

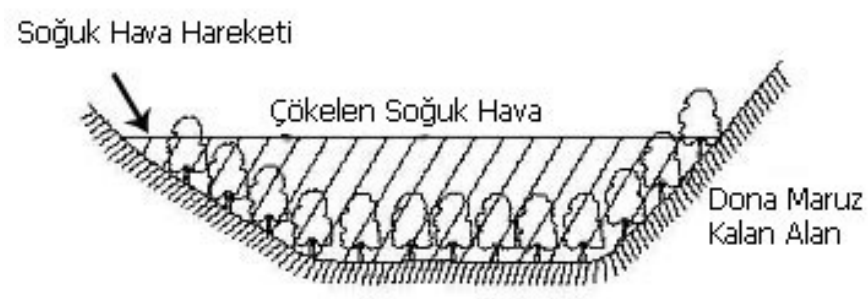

Şekil 13. Vadilerde don riski taşıyan soğuk alanlar (Şahin 1996)

\subsection{Büyükesat Vadisi Rüzgar Hareketleri}

Büyükesat Vadisi'nde eşyükselti eğrileri üzerinden elde edilen arazi modelinden ve rüzgarın vadiler içindeki hareketi bilgilerinden yola çıkılarak, vadi içindeki rüzgar hareketin Şekil 14'deki gibi olduğu anlaşılmaktadır. Gündüzleri kuzey yönünden güneye doğru ve tabandan yamaçlara doğru hareket eden hava, geceleri tam tersi bir hareket izleyerek şehre doğru kuzeye akmakta ve soğuk havanın hareketi vadi tabanına doğru olmaktadır. 


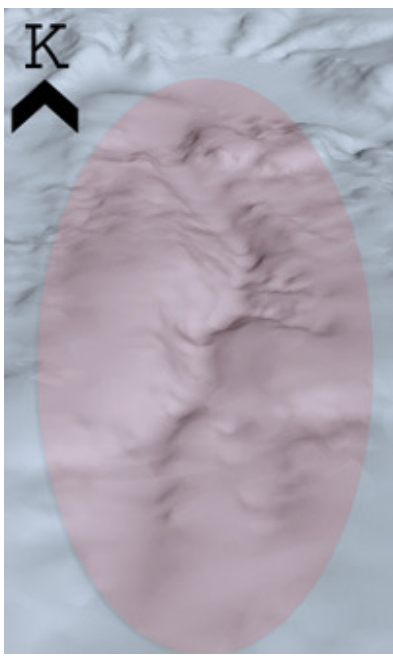

A

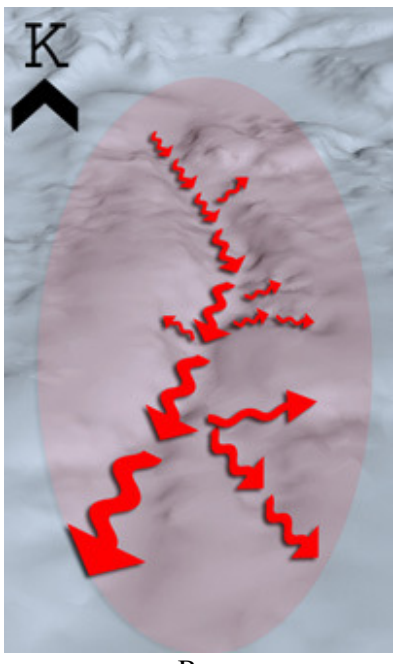

B

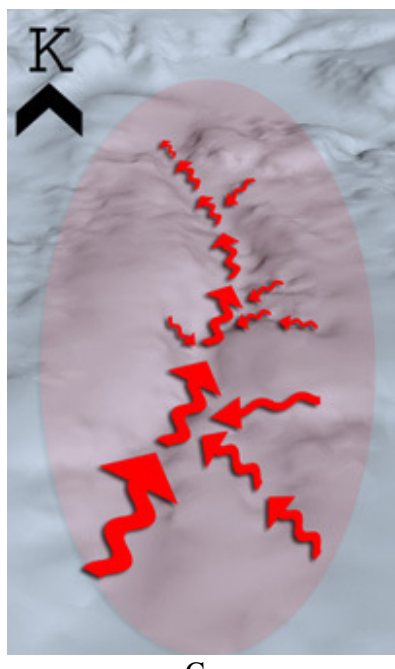

C

Şekil 14 Büyükesat vadisi rüzgar hareketleri.

(A: Büyükesat Vadisi B: Gündüz rüzgar hareketi C: Gece rüzgar hareketi)

Vadi içi rüzgar hareketlerine bağlı olarak geceleri vadi tabanına akan soğuk hava burada soğuk bir kuşak oluşturarak don riski meydana getirmektedir (Şekil 15). Bu alanlar vadi tabanında yapılacak çalışmalardaki alan seçimlerinde göz önünde bulundurulmalıdır.

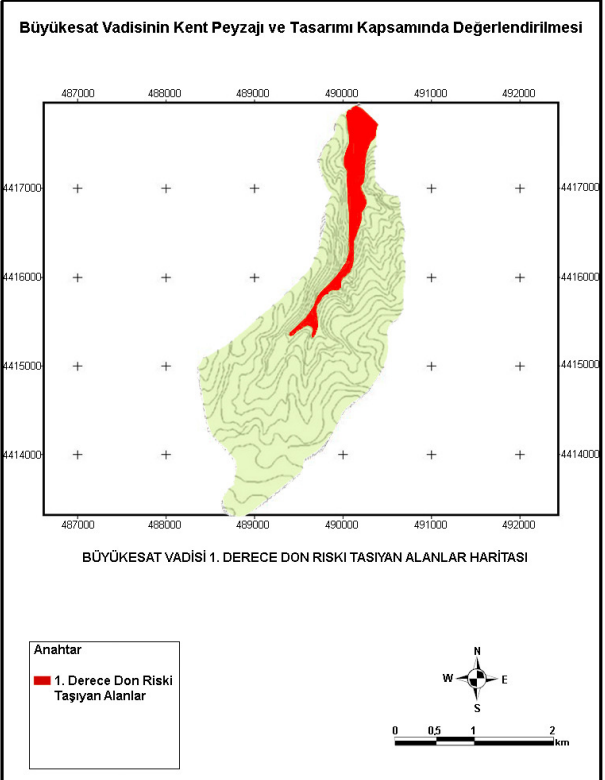

Şekil 15 Çalışma alanı 1. derece don riski taşıyan alanlar haritası. 


\section{Sonuç ve Tartışma}

Vadiler sahip oldukları içe bakar yamaçlar, vadi içlerindeki rüzgar hareketleri, vadi tabanında oluşan ve don riski taşıyan alanlar ve güneş hareketlerine bağlı gölgelik alanların oluşması bakımlarından, bitkilendirme çalışmalarında dikkat edilmesi gereken alanlar olmaktadır. Bu alanlarda hem kullanılacak bitki türleri, hem bitkilendirmenin yapılacağı alan hem de bitkilendirme tekniği önem kazanmaktadır.

Yapılan bütün analiz çalışmaları 1şı̆̆ı altında Büyükesat Vadisi’nde yapılacak bitkilendirme çalışmalarında bazı hususlara dikkat edilmesi gerektiği ortaya çıkmıştır.

\subsection{Kullanılabilecek Bitki Türleri}

Aran'a (1948) göre bu tip alanlarda "genel olarak" uygulanması gereken bitkilendirme tekniği Şekil 16'da gösterilmiştir. Buna göre, alandaki kurak yüksek sırtlar ve yamaçlarda ibreli ağaçlar kullanılmalıdır, bu ağaçlar sırtların en yüksek kısımları ile bu sırtları dere içlerine bağlayan yamaçların üst kısımlarında yer almalıdır.

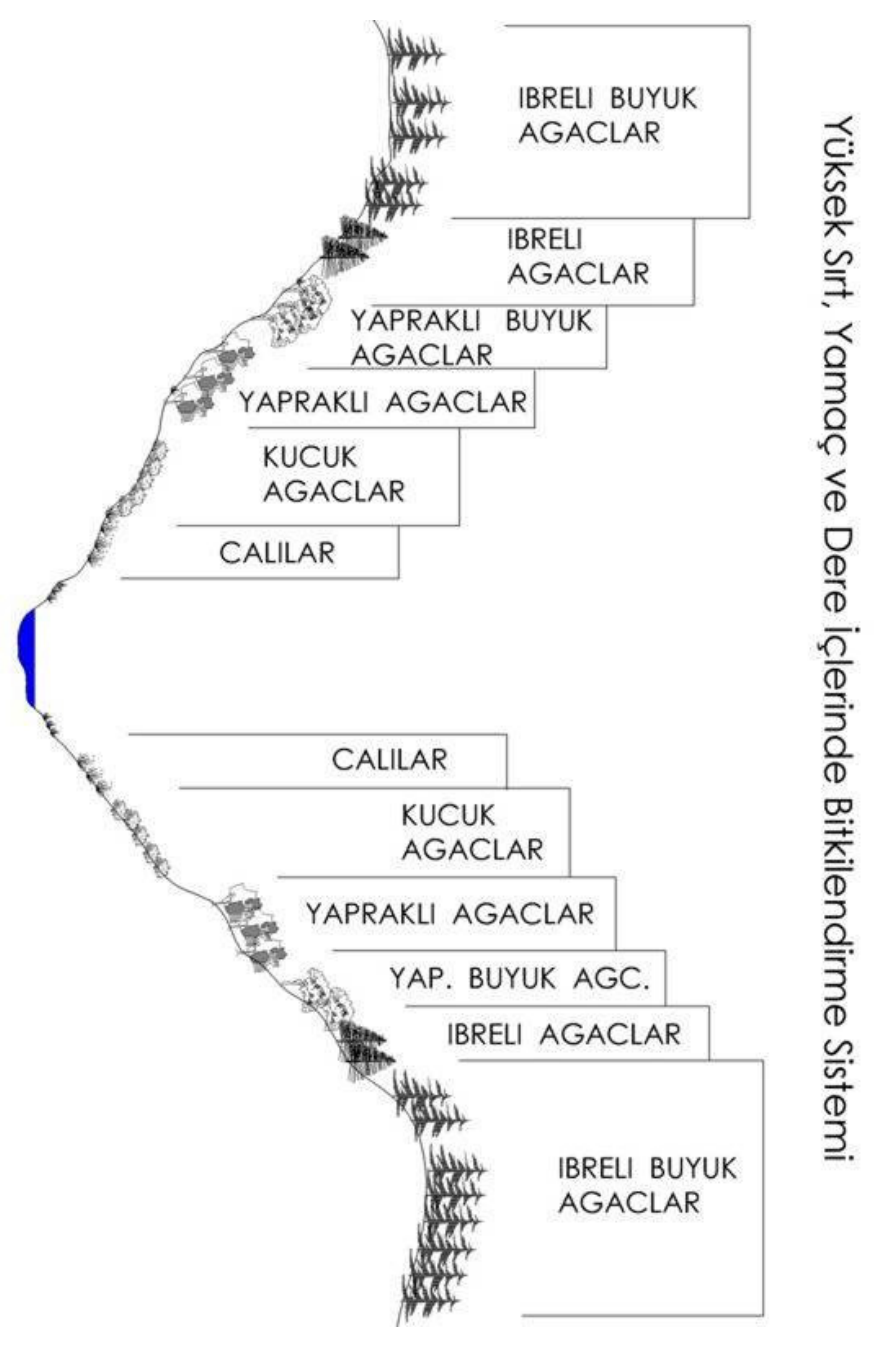

Şekil 16 Yüksek sırt, yamaç ve dere içlerinde öneri bitkilendirme tekniği. 
Yapılacak bu bitkilendirmede ağaçlar geniş ve saf topluluklar halinde kullanılmalıdır. İbreli ağaç ve çalılar bu grupları birleştirici öge olarak kullanılmalıdır. Bu alanlarda boylu olarak Abies bornmülleriana, Pinus nigra, Pinus sylvestris ve Thuja orientalis, küçük ağaçlar olarak da Juniperus oxycedrus, Juniperus excelsa, Juniperus nana, Juniperus sabina ve Juniperus communis türleri kullanılabilir.

Yüksek sırtları dere içlerine bağlayan yamaçların alt kısımları yapraklı ağaçlara ayrılmalıdır. Buralarda da kitle ağaçlandırması yapılmalıdır ancak tür seçim şansı daha fazla olduğundan fazla sayıda grup kullanılabilir. Bu bitki gruplarının arasına küçük ağaçlar ve yüksek çalılar yerleştirilebilir.

$\mathrm{Bu}$ alanlarda sik gruplar olarak, Carpinus betulus, Koelreuteria paniculata, Quercus pedunculiflora, Quercus aegilops ve Ulmus campestris; seyrek gruplar olarak ise Ailanthus glandulosa, Gleditschia triacanthos ve Quercus cerris kullanılabilir. Yine bu alanlarda yapılacak bitkilendirme çalışmalarında küçük ağaç ve yüksek çalı grupları olarak Amorpha fruticosa, Acer capmestris, Acer opalus, Amelanchier vulgaris, Colutea arborescens, Colutea cilicica, Crataegus türleri, Cytisus laburnum, Mespilus germanica, Paliurus aculeatus, Quercus infectoria, Rhus coriaria ve Sambucus nigra türleri değerlendirilebilir.

Dere içlerine yaklaştıkça bu bitkilendirme yerini çalılığa bırakmalıdır. Bu alanlarda çalılar ve soliter olarak küçük ağaçlar kullanılmalıdır. Bu tip alanlarda yapılabilecek bitkilendirme çalışmalarında kullanılabilecek bitkileri üç gruba ayırabiliriz; Soliter olarak kullanılabilecek bitkiler Koelreuteria paniculata, Quercus cerris, Quercus aegilops ve Populus alba nivea olarak siralanabilir. Dere yamaçlarındaki çalı gruplarında; Amorpha fruticosa, Amelanchier vulgaris, Amygdalus webii, Amygdalus orientalis, Berberis crataegina, Colutea arborescens, Colutea cilicica, Celtis tournefortii, Cistus laurifolius, Cotoneaster numularia, Jasminum fruticans, Lonicera etrusca, Lycium barbanum, Rosa türleri ve Viburnum lantana kullanılabilir. Dere tabanında kullanılabilecek çalı grupları ise; Berberis thunbergii var atropurpurea, Crataegus pyrcantha, Cytisus laburnum, Evonymus europea, Hippophae rhamnodies, Lonicera caprifolium, Ligustrum vulgare, Rosa türleri, Rubus tomentosus, Salix grandifolia, Salix purpurea, Sorbus graeca ve Tamarix pallasii türleri arasından seçilebilir.

\subsection{Büyükesat Vadisi Bitkilendirme Olanakları}

Şahin'e (1996) göre; sahip oldukları biyolojik, ekolojik, kültürel ve sosyo-ekonomik özellikleri nedeni ile, kent içi ve yakın çevresindeki akarsular ve vadiler için bilimsel ve akılcı yoldan bir planlama yaklaşımı gerekli ve zorunludur.

$\mathrm{Bu}$ gibi alanlarda rastlantısal seçimlerin yerine, alan envanter ve analiz çalışmaları sonucunda kullanımlar için en uygun alanlar ve en uygun materyal seçimi yapılmalıdır.

Buna göre Büyükesat Vadisi’nde yükseklik grupları 897-1126m aralığındadır. Tür seçimi yapılırken bu özellik göz önünde bulundurulmalıdır.

Çalışma alanda özellikle dere yatağı ve yakın çevresindeki yamaçlarda eğim değeri yüksektir (Şekil 3.4). Buralarda yapılacak bitkilendirme çalışmalarında toprağı tutan bitki türlerinin seçilmesi olumlu sonuçlar doğuracaktır.

Bakı analizine göre dere yatağının batısında kalan alanlar genellikle doğu ve güney doğu bakarlı alanlardır. Vadinin dere yatağının karşısında kalan yamaçları ise genel de batı, kuzey ve kuzey batı bakarlı alanlardır (Şekil 3.5). Buralarda yapılacak tür seçimlerde bakı analizinden yararlanılması, başarılı bir bitkilendirme çalışması için önemlidir.

Çalışma alanında güneşin günlük ve mevsimlik hareketleri sonucunda kısmen ve sürekli gölgede kalan alanlar meydana gelmektedir. Özellikle yıl boyu hiç direk güneş 1şığı almayan alanlarda (Şekil 3.11) tür seçiminde dikkatli olunması gerekmektedir.

Büyükesat Vadisi içinde, rüzgar hareketleri sonucunda özellikle gece geç saatlerde ve sabah erken saatlerde don riski meydana gelebilecek alanlar bulunmaktadır (Şekil 3.15). Yine bu alanlarda yapılması muhtemel bitkilendirme çalışmalarında bu şartlara dayanıklı bitki türlerinin seçilmesi doğru olacaktır. 
Ayrıca vadi, güney kuzey yönünde uzanan ve topografik yapısından dolayı kentin hava sağlığını etkileyebilecek bir yerde konumlanmıştır. Vadide yapılacak bitkilendirme çalışmalarda bu hava akımının sürekliliğinin kesilmemesine dikkat edilmelidir.

\section{Kaynaklar}

Anonim, 2007. Konya - Isparta Planlama Bölgesi 1/100.000 Ölçekli Çevre Düzeni Planı Araştırma Raporu, Erişim Tarihi 23.08.2007.

http://www.ispartacevreorman.gov.tr/rapor/2_3_bolum_topografya_jeomorfoloj1.pdf

Aran, S. 1948. Orta Anadolu Süs Bahçeciliği İçin Ziynet ağaçları Temini. Ankara Üniversitesi Ziraat Fakültesi Yayınları Sayı:2, Ankara Üniversitesi Basımevi, Ankara.

Eser, D. ve Geçit, H.H. 2007. Ekoloji. Ankara Üniversitesi Ziraat Fakültesi Yayınları, Yayın No: 1559, Ders Kitabi:512, Ankara Üniversitesi Basımevi, Ankara.

İzbırak, R. 1977. Sistematik Jeomorfoloji, Ankara Üniversitesi Dil ve Tarih Coğrafya Fakültesi Yayınları, Sayfa 39, Ankara.

Şahin, Ş. 1996. Dikmen Vadisi Peyzaj Potansiyelinin Saptanması ve Değerlendirilmesi Üzerine Bir Araştırma, Ankara Üniversitesi Fen Bilimleri Enstitüsü Peyzaj Mimarlığı Anabilim Dalı, Doktora Tezi, Ankara.

Usno, 2007. Sun or Moon Altitude/Azimuth Table, Astronomical Applications Department, http://aa.usno.navy.mil/data/docs/AltAz.php\#formb

Yüksel, Ü.D. 2005. Ankara Kentinde Kentsel Isı Adası Etkisinin Yaz Aylarında Uzaktan Algılama Ve Meteorolojik Gözlemlere Dayalı Olarak Saptanması ve Değerlendirilmesi Üzerinde Bir Araştırma, Ankara Üniversitesi Fen Bilimleri Enstitüsü Peyzaj Mimarlığı Anabilim Dalı Doktora Tez Çalışması, Ankara. 